\title{
New Aggressive Colletotrichum gloeosporioides Strains on Stylosanthes scabra Detected by Virulence and DNA Analysis
}

\author{
S. Chakraborty and R. Perrott, Commonwealth Scientific and Industrial Research Organization, Tropical Agri- \\ culture, Co-operative Research Centre for Tropical Plant Pathology, University of Queensland, Australia 4072; and \\ N. Ellis and M. R. Thomas, CSIRO Mathematical and Information Sciences, 306 Carmody Road, St. Lucia, \\ Queensland, Australia 4067
}

\begin{abstract}
Chakraborty, S., Perrott, R., Ellis, N., and Thomas, M. R. 1999. New aggressive Colletotrichum gloeosporioides strains on Stylosanthes scabra detected by virulence and DNA analysis. Plant Dis. 83:333-340.

Widespread use of Stylosanthes scabra cv. Seca to improve native pastures in northern Australia makes it necessary to monitor changes in the anthracnose pathogen, Colletotrichum gloeosporioides, because new damaging races have arisen to devastate many agronomically promising cultivars in the past. A total of 103 isolates collected during the past 20 years were analyzed by using virulence and molecular markers to determine whether aggressive strains have evolved in the field. Data on severity for eight host differentials were obtained from a greenhouse assay and analyzed by linear discriminant functions developed from existing data on 182 isolates of known races. A molecular analysis of a subset of 21 isolates by random amplified polymorphic DNA (RAPD) and electrophoretic karyotyping gave comparable results for both markers, although electrophoretic karyotyping detected a higher level of polymorphism. The majority of the 103 isolates were placed into three groups on the basis of RAPD analysis. Virulence analysis detected isolates that were highly aggressive toward Seca. During the past 20 years, the frequency of aggressive isolates has increased. Many of the aggressive isolates were collected during the 1990s, and one had a distinct RAPD genotype. The lack of a strong association between RAPD genotypes and pathogen races suggests that races have arisen independently within each genetic group. This work highlights the need for regular monitoring of the pathogen population.
\end{abstract}

Additional keywords: genetic groups, multivariate analysis, pathogenic groups, race surveys

Pasture legumes of the genus Stylosanthes, introduced from Central and South America, have been among the most successful in improving livestock nutrition and production and soil fertility in the tropical and subtropical regions of Australia. More than 1 million ha of native pastures have been oversown with cultivars of mainly S. scabra Vog. and S. hamata (L.) Taub. This area is currently increasing by 100,000 ha per year (6). The recent release of two new cultivars of $S$. seabrana will further extend the range of soil types and climatic zones in which Stylosanthes spp. can be successfully utilized in Australia.

Anthracnose, caused by Colletotrichum gloeosporioides (Penz.) Penz. \& Sacc. in Penz., remains a major threat to commercial utilization of Stylosanthes spp. (13). During the 1970s, this disease devastated an estimated 500,000 ha of highly susceptible cultivars of $S$. humilis Kunth (6). Al-

Corresponding author: S. Chakraborty

E-mail: sukumar.chakraborty@tag.csiro.au

Accepted for publication 12 December 1998.

Publication no. D-1999-0205-01R

(C) 1999 The American Phytopathological Society though this species has since been replaced with more resistant cultivars of $S$. scabra and $S$. hamata, anthracnose continues to cause losses in seed and herbage yield (9), since none of the commercial cultivars is completely resistant.

C. gloeosporioides shows considerable variation in virulence in Australia, and two biotypes of the pathogen, distinguished by host range, morphology, symptomatology and genetic characteristics (13,21), have been recorded. Biotype A is pathogenic on all species of Stylosanthes while biotype B is pathogenic mainly on $S$. guianensis (Aubl.) Sw. Because S. guianensis cultivars are suited only to a limited geographical area in Australia, biotype A is economically more significant, and discussions in this paper are restricted to this biotype.

C. gloeosporioides has readily adapted to resistant cultivars following their release. S. scabra cv. Fitzroy was productive over a large area of central Queensland but was discarded within 5 years of its release after highly aggressive strains severely damaged stands. Similarly, a new race infecting $S$. scabra cv. Seca was discovered within 6 years of release of this highly resistant cultivar (8). Although only minor damage to commercial Seca was noticed in an earlier work (14), industry reliance on Seca as the single most important cultivar dictates that regular surveys be carried out to determine whether more aggressive strains are developing on Seca. Given that virulence also measures relative aggressiveness (25), tools such as a recently described multivariate technique for the analysis of pathogenic variation in $C$. gloeosporioides (5) can be used to analyze aggressiveness.

DNA markers can replace time-consuming and often variable (4) pathogenicity assays if there is strong correlation between pathogenicity and molecular markers. Selection-neutral random amplified polymorphic DNA (RAPD) markers have been used to differentiate races of Fusarium solani f. sp. cucurbitae (7). Although differences in restriction fragment length polymorphism (RFLP) between the two biotypes of $C$. gloeosporioides that infect Stylosanthes are well established (1), only limited information is available on the level of genetic variation within each biotype, and correlation between molecular groups and races has not been studied. Using four biotype A and seven biotype $\mathrm{B}$ isolates, Masel et al. (22) found that none of the isolates had the same minichromosome complement, indicating that electrophoretic karyotyping (EK) can be a powerful tool in the analysis of the C. gloeosporioides population. A detailed molecular analysis of the Australian biotype A pathogen population is currently lacking.

Using field surveys, we collected isolates of C. gloeosporioides from commercial seed-production plots and other sites in Queensland, Australia, where Stylosanthes is used in commercial pastures. We examined the level of diversity in 103 isolates collected during more than 20 years using virulence and molecular analysis. The objectives of this study were to determine (i) whether more aggressive strains capable of damaging the cultivar Seca were present in the pathogen population collected during a period of time and (ii) whether there was a relationship between DNA polymorphism and variation in virulence and aggressiveness in the pathogen population that would allow the use of molecular markers to identify pathogen races.

\section{MATERIALS AND METHODS}

Isolates. Samples of infected Stylosanthes leaves and stems were collected from different areas in Queensland, Aus- 
tralia, and single-spore isolates of C. gloeosporioides were obtained from these samples. Selected single-spore isolates were also obtained from the existing collections of J. Irwin (University of Queensland) and R. Davis (Queensland Department of Primary Industries). All 103 isolates, including reference isolates cs89, sr24, 21365, wrs20, and wrs32, which represent the current biotype A races in Australia, were grown on oatmeal agar and stored as lyophilized cultures (Table 1). All reference isolates are virulent on Fitzroy and avirulent on accession 93116 (5). Race 1, represented by the reference isolate $\operatorname{cs} 89$, is virulent only on Fitzroy. Race 2 (isolate 21365) is virulent on $S$. viscosa $\mathrm{Sw}$. accession 33941 (13). Race 3 (isolate sr24) is virulent on
Seca. Races 4 (wrs32) and 4a (wrs20) are most severe on 36260 . Differences in susceptibility to races 4 and $4 \mathrm{a}$ in Q10042 are quantitative, and in some tests similar disease severity levels on Q10042 have been recorded with both races (4). These two isolates could not be distinguished from each other by multivariate analysis and have since been grouped as race 4 (5).

Assessment and analysis of pathogenic variation. Pathogenic variation in $C$. gloeosporioides isolates infecting $S$. scabra was assessed by using six differentials comprising cultivars Fitzroy and Seca and accessions 36260, 55860, Q10042, and 93116 (5). Of these, Fitzroy, Seca, 36260, Q10042, and 93116 form the main group of differentials necessary to identify races.
Accession 55860 is partially resistant to all isolates tested so far and does not contribute to the separation of races (5). In this work, 55860 was replaced with 110354 to detect potential virulence toward this highly resistant accession. In addition, two $S$. viscosa accessions, 33941 and 34904, were used to detect race 2 (13). Six-week-old seedlings of the differentials were raised in a greenhouse in sandy loam soil in $50-\mathrm{mm}^{2}$ plastic pots (Kwik pots, Arthur Yates \& Co., Australia). Thirty pots were randomized in a tray to contain three to four replicate seedlings of each host differential. Seedlings in each tray were inoculated with a suspension $\left(10^{6}\right.$ conidia/ml $)$ of a single isolate of $C$. gloeosporioides by spraying to incipient run off and then

Table 1. Source and characteristics of Colletotrichum gloeosporioides isolates used in this study

\begin{tabular}{|c|c|c|c|c|c|}
\hline Isolate & Year & Host & Location & Race & RAPD cluster \\
\hline *uq 14 & 1970s & Stylosanthes scabra & North Qld. & 3 & $\mathrm{G}$ \\
\hline$* 21365$ & 1978 & S. viscosa 33941 & Townsville & 2 & $\mathrm{~J}$ \\
\hline $\operatorname{sr} 13$ & $1980 \mathrm{~s}$ & S. fruticosa $41219 \mathrm{~A} 2$ & Southedge & 1 & $\mathrm{~J}$ \\
\hline $\operatorname{sr} 23$ & 1982 & S. guianensis 18750 & Southedge & 1 & $\mathrm{C}$ \\
\hline wrs8 & 1982 & S. montevidensis 11494 & Walkamin & 1 & $\mathrm{C}$ \\
\hline wrs10 & 1982 & S. hamata 75169 & Walkamin & 1 & $\mathrm{~J}$ \\
\hline wrs15 & 1982 & S. hamata 57248 & Walkamin & 1 & $\mathrm{~J}$ \\
\hline wrs18 & 1982 & S. fruticosa 60354 & Walkamin & 1 & $\mathrm{~J}$ \\
\hline$*_{\mathrm{s}} 4$ & 1982 & S. scabra cv. Fitzroy & Southedge & 1 & $\mathrm{~J}$ \\
\hline sr4-1 & 1982 & S. scabra cv. Fitzroy & Southedge & 3 & $\mathrm{D}$ \\
\hline wrs14 & 1982 & S. hamata 75164 & Walkamin & 3 & $\mathrm{~J}$ \\
\hline *wrs20 & 1982 & S. scabra 36260 & Walkamin & $4 a$ & G \\
\hline wrs3 & 1982 & S. capitata $40240 \mathrm{~B}$ & Walkamin & Unclassified & $\mathrm{J}$ \\
\hline wrs11 & 1982 & S. capitata 55840 & Walkamin & Unclassified & A \\
\hline wrs34 & 1982 & S. guianensis cv. Endeavour & Walkamin & Unclassified & $\mathrm{J}$ \\
\hline$*$ sr30 & 1984 & S. hamata cv. Verano & Southedge & 1 & $\mathrm{~J}$ \\
\hline wrs35 & 1984 & S. guianensis 79639 & Walkamin & 1 & $\mathrm{~L}$ \\
\hline *wrs33 & 1984 & S. scabra 36260 & Walkamin & 3 & $\mathrm{D}$ \\
\hline$*_{\mathrm{s}} 24$ & 1984 & S. scabra cv. Seca & Southedge & 3 & $\mathrm{D}$ \\
\hline$*_{\mathrm{wrs} 51}$ & 1984 & S. fruticosa 41219 & Walkamin & 4 & $\mathrm{G}$ \\
\hline *wrs32 & 1984 & S. scabra Q10042 & Walkamin & 4 & G \\
\hline$* \operatorname{cs} 18$ & 1986 & S. hamata 75166 & Woodleigh & 1 & $\mathrm{~J}$ \\
\hline $\operatorname{cs} 20$ & 1986 & S. hamata cv. Verano & Springs Rd. & 1 & $\mathrm{~J}$ \\
\hline $\operatorname{cs} 133$ & 1986 & Stylosanthes mixture & Springs Rd. & 3 & $\mathrm{H}$ \\
\hline $\operatorname{cs} 137$ & 1986 & Stylosanthes mixture & Springs Rd. & 3 & $\mathrm{G}$ \\
\hline T7G22 & 1986 & Stylosanthes mixture & Springs Rd. & 4 & I \\
\hline T8G7 & 1986 & Stylosanthes mixture & Springs Rd. & 4 & $\mathrm{~J}$ \\
\hline cs136 & 1986 & Stylosanthes mixture & Springs Rd. & 4 & $\mathrm{~J}$ \\
\hline$* \operatorname{cs} 116$ & 1987 & S. scabra Q10042 & Samford & 1 & $\mathrm{~J}$ \\
\hline $\operatorname{cs} 68$ & 1987 & S. scabra Q10042 & Boowoogum & 1 & $\mathrm{~J}$ \\
\hline$* \operatorname{cs} 89$ & 1987 & S. scabra cv. Fitzroy & Samford & 1 & $\mathrm{~J}$ \\
\hline$* \operatorname{cs} 105$ & 1987 & S. scabra cv. Fitzroy & Samford & 3 & $\mathrm{D}$ \\
\hline$* \operatorname{cs} 87$ & 1987 & S. scabra cv. Fitzroy & Samford & 3 & $\mathrm{D}$ \\
\hline $\operatorname{cs} 69$ & 1987 & S. scabra cv. Fitzroy & Boowoogum & 3 & $\mathrm{~K}$ \\
\hline$* \operatorname{cs} 231$ & 1988 & S. scabra cv. Seca & Samford & 1 & $\mathrm{D}$ \\
\hline $\operatorname{cs} 157$ & 1988 & S. scabra 55860 & Byrne valley & 1 & $\mathrm{G}$ \\
\hline$* \operatorname{cs} 232$ & 1988 & S. scabra cv. Fitzroy & Samford & 3 & $\mathrm{~J}$ \\
\hline$* \operatorname{cs} 218$ & 1988 & S. scabra Q10042 & Samford & 3 & $\mathrm{D}$ \\
\hline cs154 & 1988 & S. scabra cv. Fitzroy & Byrne valley & 3 & G \\
\hline $\operatorname{cs} 158$ & 1988 & S. scabra Q10042 & Byrne valley & 3 & $\mathrm{G}$ \\
\hline $\operatorname{cs} 141$ & 1988 & S. scabra cv. Seca & Springmount & 3 & $\mathrm{G}$ \\
\hline cs144 & 1988 & S. scabra mixture & Springmount & 3 & $\mathrm{~F}$ \\
\hline$* \operatorname{cs} 239$ & 1988 & S. scabra cv. Seca & Samford & 3 & $\mathrm{D}$ \\
\hline$* \operatorname{cs} 204$ & 1988 & S. scabra cv. Seca & Samford & 3 & $\mathrm{D}$ \\
\hline cs199 & 1988 & S. scabra Q10042 & Samford & 4 & $\mathrm{G}$ \\
\hline$* \operatorname{cs} 233$ & 1988 & S. scabra 36260 & Samford & 4 & G \\
\hline wrs52 & 1989 & S. guianensis & Walkamin & 1 & $\mathrm{~B}$ \\
\hline $\operatorname{cs} 309$ & 1989 & S. scabra Q10042 & Boowoogum & 1 & G \\
\hline $\operatorname{cs} 310$ & 1989 & S. scabra cv. Fitzroy & Wycheproof & 1 & $\mathrm{~F}$ \\
\hline$* \operatorname{cs} 273$ & 1989 & S. scabra 55857 & Cedarvale & 1 & $\mathrm{G}$ \\
\hline
\end{tabular}

a The 21 isolates used to compare polymorphism by electrophoretic karyotype and random amplified polymorphic DNA (RAPD) markers are indicated by asterisks. 
maintained in a dew chamber for $48 \mathrm{~h}$. Isolates were grown on oatmeal agar for 7 days, and cultures were flooded with sterile distilled water to obtain conidial suspensions. Seedlings were visually examined for percentage of leaf area diseased 10 days after inoculation and rated on a scale of 0 to 9 ( 0 , no visible symptoms; 1,1 to $3 \% ; 2,4$ to $6 \% ; 3,7$ to $12 \% ; 4,13$ to $25 \% ; 5,26$ to $50 \%$; 6,51 to $75 \%, 7,76$ to $87 \% ; 8,88$ to $94 \%$; and 9,95 to $100 \%$ leaf area diseased) (4). Because of limited greenhouse space, only a small number of isolates were screened at any one time. At each inoculation, one or more of the reference isolates were included for comparison.

The bioassay was repeated once, and data from the two runs were averaged for an analysis of pathogenic variation. Data on disease severity of each isolate on the host differentials were $\log _{\mathrm{e}}($ severity +1$)$ transformed and analyzed by a multivariate technique. In this analysis, a data set containing disease severity on the host differentials for isolates of known races was used to develop linear discriminant functions (LDF), which were applied to the data on disease severity of new isolates to ascertain their racial grouping. Previous work on 182 Australian isolates found three major races within the population infecting S. scabra. Data on these 182 isolates were used as the training set to develop LDF for the three races. Details of this procedure have been reported (5).

Molecular analysis. A subset of 21 isolates representing races $1,2,3,4$, and $4 \mathrm{a}$ was analyzed by RAPD and EK to select an easy-to-use marker system for screening biotype A isolates. Arbitrary primers used for RAPD analysis were selected from a preliminary study in which seven isolates, including the five reference isolates, were screened with 143 arbitrary decanucleotide primers (Operon Technologies, Alameda, CA). Of these, six primers, AN 11 (GTCCATGCAG), L02 (TGGGCGTCAA), L11 (ACGATGAGCC), P15 (GGAAGCCAAC), P16 (CCAAGCTGCC) and Q20 (TCGCCCAGTC), gave scorable polymorphic bands. All 103 isolates were subsequently screened by RAPD analysis.

For RAPD analysis, single-spore cultures were multiplied on oatmeal agar, and DNA was extracted by the method of Edwards et

Table 1. (continued from preceding page)

\begin{tabular}{|c|c|c|c|c|c|}
\hline Isolate & Year & Host & Location & Race & RAPD cluster \\
\hline $\operatorname{cs} 288$ & 1989 & S. scabra cv. Fitzroy & Lynford & 1 & G \\
\hline $\operatorname{cs} 282$ & 1989 & S. scabra cv. Seca & Byrne valley & 3 & $\mathrm{G}$ \\
\hline $\operatorname{cs} 295$ & 1989 & S. scabra mixture & Byrne valley & 3 & $\mathrm{G}$ \\
\hline $\operatorname{cs} 302$ & 1989 & S. scabra mixture & Byrne valley & 3 & $\mathrm{G}$ \\
\hline $\operatorname{cs} 325$ & 1989 & S. scabra mixture & Byrne valley & 3 & $\mathrm{G}$ \\
\hline $\operatorname{cs} 290$ & 1989 & S. scabra cv. Seca & Tedlands & 3 & G \\
\hline $\operatorname{cs} 298$ & 1989 & S. scabra 55860 & Tedlands & 3 & $\mathrm{G}$ \\
\hline $\operatorname{cs} 312$ & 1989 & S. scabra cv. Fitzroy & Tedlands & 3 & $\mathrm{G}$ \\
\hline $\operatorname{cs} 276$ & 1989 & S. scabra cv. Fitzroy & Wycheproof & 3 & $\mathrm{G}$ \\
\hline $\operatorname{cs} 286$ & 1989 & S. scabra 55857 & Wycheproof & 3 & G \\
\hline $\operatorname{cs} 287$ & 1989 & S. scabra Q10042 & Wycheproof & 3 & $\mathrm{G}$ \\
\hline $\operatorname{cs} 299$ & 1989 & S. scabra 36260 & Wycheproof & 3 & G \\
\hline $\operatorname{cs} 291$ & 1989 & S. scabra Q10042 & Cedarvale & 3 & $\mathrm{G}$ \\
\hline $\operatorname{cs} 296$ & 1989 & S. scabra cv. Seca & Cedarvale & 3 & $\mathrm{E}$ \\
\hline $\operatorname{cs} 274$ & 1989 & S. scabra Q10042 & Mt. Pluto & 3 & $\mathrm{G}$ \\
\hline $\operatorname{cs} 275$ & 1989 & S. scabra 55857 & Mt. Pluto & 3 & $\mathrm{G}$ \\
\hline $\operatorname{cs} 280$ & 1989 & S. scabra mixture & Mt. Pluto & 3 & G \\
\hline $\operatorname{cs} 285$ & 1989 & S. scabra cv. Fitzroy & Mt. Pluto & 3 & $\mathrm{G}$ \\
\hline $\operatorname{cs} 305$ & 1989 & S. scabra mixture & Mt. Pluto & 3 & $\mathrm{G}$ \\
\hline $\operatorname{cs} 289$ & 1989 & S. scabra cv. Fitzroy & Boowoogum & 4 & $\mathrm{G}$ \\
\hline $\operatorname{cs} 292$ & 1989 & S. scabra Q10042 & Boowoogum & 4 & G \\
\hline $\operatorname{cs} 297$ & 1989 & S. scabra 55860 & Cedarvale & 4 & G \\
\hline $\operatorname{cs} 307$ & 1989 & S. scabra 36260 & Cedarvale & 4 & $\mathrm{G}$ \\
\hline $\operatorname{cs} 300$ & 1989 & S. scabra 55857 & Lynford & 4 & G \\
\hline $\operatorname{cs} 304$ & 1989 & S. scabra cv. Fitzroy & Byrne valley & Unclassified & $\mathrm{G}$ \\
\hline $\operatorname{cs} 294$ & 1989 & S. scabra mixture & Mt. Pluto & Unclassified & $\mathrm{G}$ \\
\hline nq220 & 1992 & S. scabra 93116 & Springmount & Unclassified & $\mathrm{D}$ \\
\hline nq244 & 1992 & S. scabra 55860 & Springmount & Unclassified & M \\
\hline nq176 & 1992 & S. scabra cv. Fitzroy & Springmount & Unclassified & $\mathrm{D}$ \\
\hline nq301 & 1992 & S. scabra cv. Fitzroy & Springmount & 3 & $\mathrm{G}$ \\
\hline nq283 & 1992 & S. scabra cv. Seca & Springmount & 3 & G \\
\hline nq297 & 1992 & S. scabra cv. Seca & Springmount & 3 & $\mathrm{D}$ \\
\hline $\operatorname{cs} 1106$ & 1993 & S. scabra mixture & Cedarvale & 3 & $\mathrm{G}$ \\
\hline $\operatorname{cs} 1096$ & 1993 & S. scabra mixture & Cedarvale & 3 & $\mathrm{G}$ \\
\hline cs 1095 & 1993 & S. scabra mixture & Cedarvale & 3 & $\mathrm{G}$ \\
\hline cs 1074 & 1993 & S. scabra cv. Seca & Cedarvale & Unclassified & G \\
\hline $\operatorname{cs} 1082$ & 1993 & S. scabra cv. Seca & Cedarvale & Unclassified & $\mathrm{G}$ \\
\hline cs 1076 & 1993 & S. scabra cv. Seca & Cedarvale & 3 & $\mathrm{G}$ \\
\hline nq124 & 1994 & S. scabra cv. Seca & Springmount & Unclassified & $\mathrm{G}$ \\
\hline nq151 & 1994 & S. scabra 36260 & Springmount & Unclassified & $\mathrm{D}$ \\
\hline nq162 & 1994 & S. scabra Q10042 & Springmount & Unclassified & $\mathrm{G}$ \\
\hline $\operatorname{cs} 1248$ & 1994 & S. scabra mixture & Cedarvale & 3 & G \\
\hline cs1199 & 1994 & S. scabra mixture & Cedarvale & 3 & $\mathrm{G}$ \\
\hline $\operatorname{cs} 1374$ & 1994 & S. scabra cv. Seca & Cedarvale & Unclassified & G \\
\hline $\operatorname{cs} 1599$ & 1996 & S. scabra cv. Seca & T. Jepperson & Unclassified & $\mathrm{G}$ \\
\hline $\operatorname{cs} 1600$ & 1996 & S. scabra cv. Seca & T. Jepperson & 3 & $\mathrm{G}$ \\
\hline $\operatorname{cs} 1443$ & 1996 & S. scabra cv. Seca & T. Jepperson & Unclassified & $\mathrm{G}$ \\
\hline $\operatorname{cs} 1571$ & 1996 & S. scabra cv. Seca & Rains, Home & Unclassified & $\mathrm{D}$ \\
\hline $\operatorname{cs} 1588$ & 1996 & S. scabra cv. Seca & North Walsh & 3 & $\mathrm{G}$ \\
\hline $\operatorname{cs} 1499$ & 1996 & S. scabra cv. Seca & Wycheproof & 1 & $\mathrm{G}$ \\
\hline $\operatorname{cs} 1559$ & 1996 & S. scabra cv. Seca & Cuzzabo & Unclassified & $\mathrm{D}$ \\
\hline $\operatorname{cs} 1566$ & 1996 & S. scabra cv. Seca & Cuzzabo & Unclassified & $\mathrm{G}$ \\
\hline $\operatorname{cs} 1517$ & 1996 & S. scabra cv. Seca & Brian Pastures & 1 & G \\
\hline
\end{tabular}


al. (10) with minor modifications. Mycelia and conidia were ground in an extraction buffer $(250 \mathrm{mM}$ Tris $\mathrm{HCl}, 200 \mathrm{mM} \mathrm{NaCl}$, $25 \mathrm{mM}$ EDTA, and 5\% sodium dodecyl sulfate), centrifuged, cleaned with phenol chloroform, and washed with chloroform. The DNA was then precipitated in ethanol. DNA from duplicate samples of each isolate was amplified by polymerase chain reaction conducted in a programmable thermocycler (MJ Research, Watertown, MA). After an initial 5-min denaturation step at $94^{\circ} \mathrm{C}, 40$ cycles consisting of $1 \mathrm{~min}$ of denaturation at $94^{\circ} \mathrm{C}, 1 \mathrm{~min}$ of annealing at $37^{\circ} \mathrm{C}$, and $2 \mathrm{~min}$ of primer extension at $72^{\circ} \mathrm{C}$ were performed. The amplification product $(30 \mu \mathrm{l})$ was electrophoresed in $1.5 \%$ agarose gel containing $40 \mu \mathrm{g}$ of ethidium bromide. Gels were run in halfstrength Tris-borate-EDTA buffer, and duplicate samples of each isolate were used for verification.

For EK analysis, conidia were obtained from single-spore cultures of isolates grown in V8 juice for 7 days with shaking. Spore blocks were prepared for pulse field electrophoresis according to Masel et al. (22). Conidia were centrifuged for $10 \mathrm{~min}$ at 4,000 rpm, and the pellet was washed with $50 \mathrm{mM}$ EDTA and resuspended in $1 \%$ lowmelting-point agarose in $125 \mathrm{mM}$ EDTA and $50 \mathrm{mM} \mathrm{Na}$ citrate $(\mathrm{pH} 5.7)$ with a lysing enzyme (Sigma Chemical Co., St. Louis, MO). Agar blocks were set in a commercial sample mold (Bio-Rad Labo- ratories, Richmond, CA). Conidia were lysed in $50 \mathrm{mM} \mathrm{Na}$ citrate with $0.4 \mathrm{M}$ EDTA and $7.5 \%$ mercaptoethanol (pH 5.7) at $45^{\circ} \mathrm{C}$ for $24 \mathrm{~h}$ and in proteinase $\mathrm{K}(\mathrm{mg} /$ $\mathrm{ml})$ in NDS buffer (0.5 M EDTA, $10 \mathrm{mM}$ Tris $\mathrm{HCl}$, and $1 \% \mathrm{~N}$-lauroylsarcosine adjusted to $\mathrm{pH} 8.0$ ) at $50^{\circ} \mathrm{C}$ for $24 \mathrm{~h}$.

A contour-clamped homogeneous electric field dynamically regulated system (CHEF-DR II, Bio-Rad) was used for gel electrophoresis in half-strength Tris-borate-EDTA buffer ( $\mathrm{pH}$ 8.0) maintained at $14^{\circ} \mathrm{C}$ with constant buffer circulation. Spore blocks were placed in wells in a $0.8 \%$ agarose gel $(14 \times 12.7 \times 1 \mathrm{~cm})($ Pharmacia, Uppsala, Sweden) and run with switch times of $20 \mathrm{~h}, 30 \mathrm{~s}$ followed by $9 \mathrm{~h}$, 90 s. Saccharomyces cerevisiae chromosomes (Bio-Rad) were used as size markers. Gels were stained with ethidium bromide, destained in distilled water, and then examined with a UV-transilluminator.

Data obtained for the 21 isolates examined by RAPD and EK and the 103 isolates examined by RAPD were analyzed separately. Data on RAPD and EK were analyzed in a similar way. RAPD bands consistently present in duplicate samples of each isolate and bands representing putative minichromosomes were scored as present or absent. For each marker system, data were pooled to examine similarities from pairwise comparison of isolates. Similarity values were calculated with the formula $F=2 m_{\mathrm{xy}} /\left(m_{\mathrm{x}}+m_{\mathrm{y}}\right)$, in which $m_{\mathrm{xy}}$ is

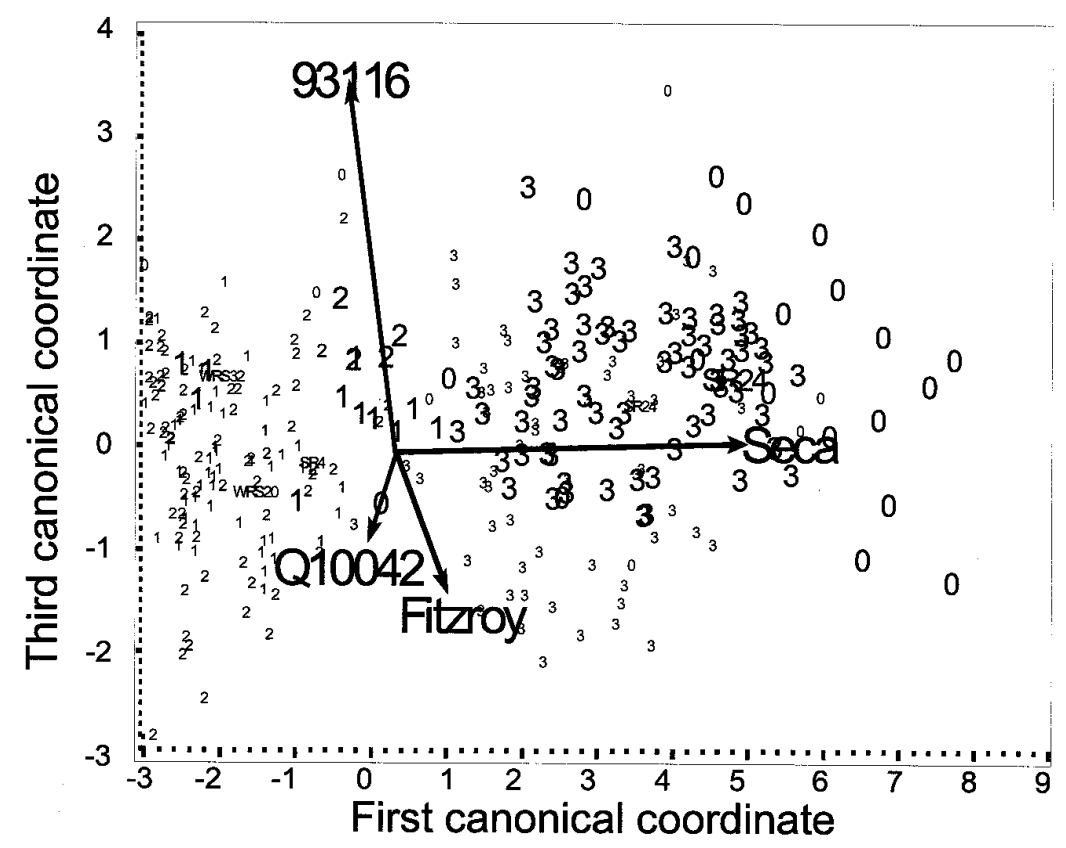

Fig. 1. Classification of 103 isolates of Colletotrichum gloeosporioides into race clusters (large numerals) by using linear discriminant functions developed from a training data set on disease severity of 182 isolates (small numerals) on differential host genotypes of Stylosanthes scabra. Unclassified isolates are represented by zeros (large numerals). The four original axes (arrows) have been projected onto the plot to relate the log-transformed scores on the differentials to the two canonical coordinates. The arrows originate from the point representing the overall mean severity of the training data set. The length of each arrow represents the change in canonical coordinates given a unit change from the mean score for each differential. For clarity, only the reference isolates have been labeled.

the number of shared bands and $m_{\mathrm{x}}$ and $m_{\mathrm{y}}$ are the number of bands in each isolate. A software package (SAS Institute, Cary, NC) was used for cluster analysis of the similarity values using the unweighted pair group method with arithmetic mean, and the procedure TREE (SAS) was used to generate a dendrogram. The SAS macro program DENDRO, developed by P. Nicholson of the University of Leeds, was used for this purpose. This program is available on-line from SAS.

\section{RESULTS}

Virulence phenotypes. As noted before (5), Fitzroy, Seca, 36260, Q10042, and 93116 were the most important differentials in discriminating among the races. No virulence toward accession 110354 was detected in any isolate. Existing data on disease severity on the six host differentials for 182 Australian isolates from races 1,3 , and 4 (5) were used as the training set to develop LDF. Except for reference isolate 21365, none of the isolates matched the race 2 virulence pattern. No LDF were developed for race 2 because its host, $S$. viscosa, is not of commercial significance in Australia. The 103 isolates were each classified into one of the three race clusters by using the LDF. Isolates that were within the 95th percentile of the distribution of within-cluster Mahalanobis distance for a given race cluster were classified as members of that race (Fig. 1). Of the 84 isolates that could be classified by the LDF, 24 were classified as race 1 , 47 as race 3 , and 13 as race 4 (Table 1 ). Race 1 isolates, virulent only on the universal suscept Fitzroy, originated from many different Stylosanthes species, including $S$. hamata, S. scabra, S. guianensis, $S$. montevidensis, and $S$. fruticosa. The more complex races 3 and 4 with virulence toward other differentials in addition to Fitzroy were isolated predominantly from S. scabra plants.

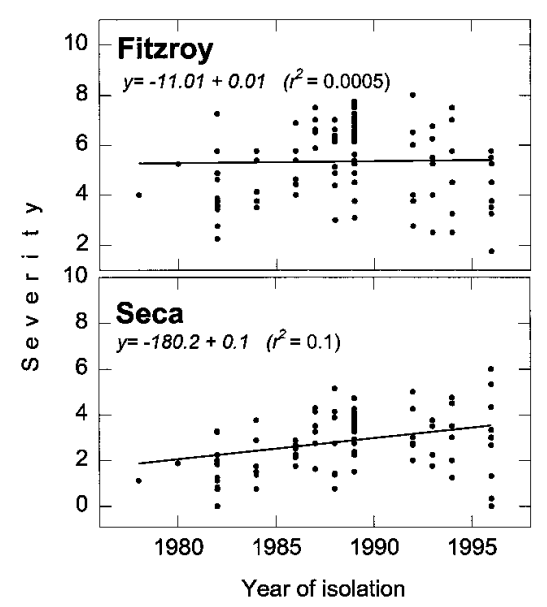

Fig. 2. Relationship between anthracnose severity on Stylosanthes scabra cultivars Fitzroy and Seca caused by Colletotrichum gloeosporioides isolates collected during 1970 to 1996. 
Nineteen isolates that did not meet the 95th percentile criterion remained unclassified (Fig. 1). Seven isolates (cs304, cs1074, cs1599, nq162, wrs3, wrs11, and wrs34) were weakly pathogenic on all differentials (data not shown). The remaining 12 were highly aggressive on Seca with mean severity ratings $>3$. Five of these, cs1443, cs1571, nq124, nq151, and nq244, produced mean severity ratings between 4 and 6 (data not shown). This is much higher than the 1 to 2.7 range of severity (5) produced on Seca by the reference isolate and others used in developing the LDF.

Of the 12 highly aggressive isolates, 11 were collected between 1992 and 1996. To determine whether isolates had become progressively more aggressive toward Seca, the relationship between the year of isolation and the severity on selected differentials was examined by linear regression analysis. A significant $(P<0.05)$ linear relationship was detected for severity on Seca with severity increasing with time. Severity on all other differentials remained unchanged over time. Data are given for Fitzroy and Seca only (Fig. 2).

Comparison of RAPD and EK markers. A total of 75 reproducible RAPD bands ranging from 240 to 2,200 bp were obtained with the six selected primers on the 21 isolates (Fig. 3). Of the DNA fragments amplified with primer AN11, seven isolates (21365, cs18, sr30, cs116, cs232, cs 89 , and sr4) had a unique band of about 1,250 bp. Primers L11, P15, P16, and Q20 also amplified similar unique fragments in all seven isolates. Primer L2 amplified a unique 1,200-bp DNA fragment in these seven isolates and in isolates uq14, $\operatorname{cs} 233$, wrs20, wrs32, wrs51, and cs273. The 21 isolates were grouped into three clusters on the basis of an analysis of the pooled data for all six primers (Fig. 4A).

Six to 11 putative minichromosomes in the $300-$ to $615-\mathrm{kb}$ range were resolved in the 21 isolates, and data are given for 15 of these isolates (Fig. 5). Of these, the 614-, 410-, and 367-kb fragments were present in all isolates; the $455-\mathrm{kb}$ fragment was present in all except sr30; and the 394-kb fragment was present in all except sr30 and cs18. Isolates could be classified into seven groups, with the majority (17) of isolates belonging to three groups. In group 1, eight isolates, cs87, cs105, cs204, cs218, cs231, cs239, sr24, and uq14, each had 10 minichromosomes of $614,533,511,455,410$, $402,394,367,342$, and $312 \mathrm{~kb}$. In group 2, five isolates, cs233, wrs20, wrs32, wrs33, and wrs51, each had eight minichromosomes of $614,538,485,455,410,402$, 394 , and $367 \mathrm{~kb}$. In group 3, four isolates, cs89, cs116, cs232, and sr4, each had six minichromosomes of $614,538,455,410$, 394 , and $367 \mathrm{~kb}$. The remaining four isolates, cs18, cs273, sr30, and 21365, each had a unique banding pattern with 7 to 11 minichromosomes. A cluster analysis was performed on EK data based on the presence or absence of the minichromosome bands, and a dendrogram, generated by the method outlined for RAPD, clearly shows the seven groups (Fig. 4B).

Overall, a higher level of polymorphism was obtained by EK than with RAPD markers. Isolates within the three RAPD groups could be further discriminated by EK analysis. Sr30, cs18, and 21365, which formed part of one RAPD cluster, could be discriminated as individual isolates on the basis of their unique EK profiles. Similarly, the unique EK profile for isolate cs 273 distinguished it from five other isolates that were in the same RAPD cluster. However, there was broad agreement between the three major genetic groups identified by the two marker systems. Of the eight isolates, sr24, cs239, cs204, wrs33, cs218, cs87, cs105, and cs231, which formed one RAPD cluster, all except wrs33 were grouped in the same EK cluster. Similarly, the majority of isolates from each of the other two RAPD clusters constituted a separate EK cluster. The logistics of the EK procedure, including the long samplepreparation time, make it unsuitable as a routine technique for screening large numbers of isolates. In addition, the diffused banding pattern obtained with EK can be difficult to visualize and score. RAPD markers were therefore chosen as easy-touse tools to characterize genetic differences between the 103 isolates.
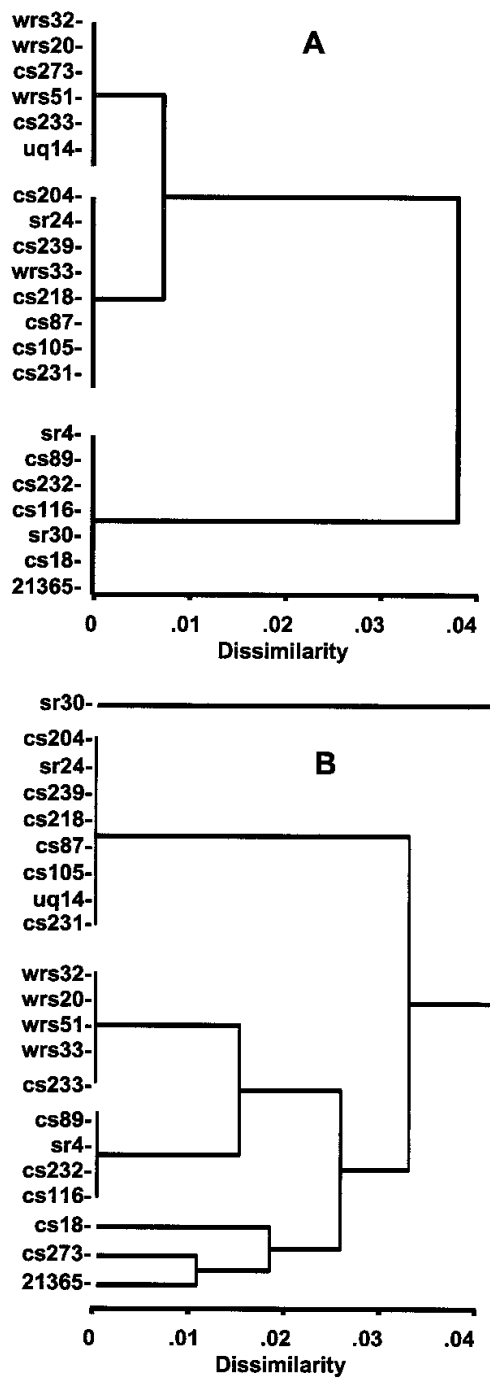

Fig. 4. Dendrogram of 21 biotype A isolates of Colletotrichum gloeosporioides infecting Stylosanthes spp. developed by (A) random amplified polymorphic DNA analysis and (B) electrophoretic karyotype analysis.

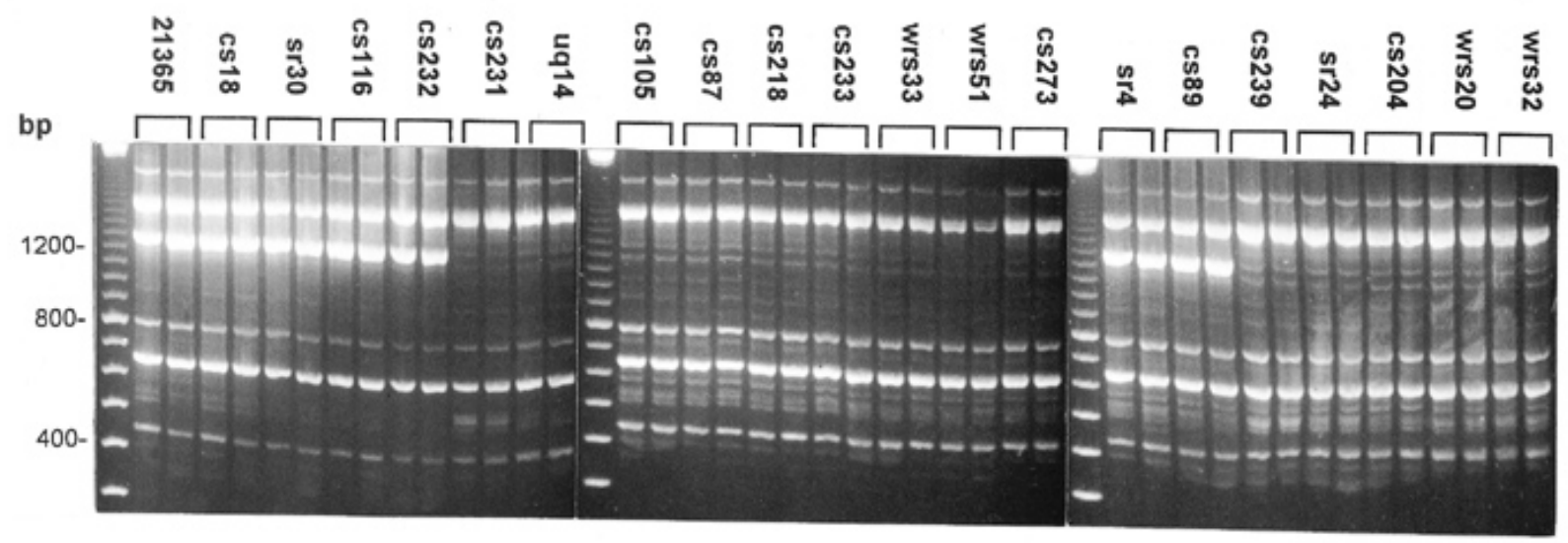

Fig. 3. Polymorphism in duplicate samples of 21 Colletotrichum gloeosporioides isolates determined by random amplified polymorphic DNA analysis with the arbitrary primer AN11. The three unmarked lanes contain 100-bp ladder DNA (Pharmacia, Uppsala, Sweden) as size markers. 
RAPD analysis of 103 isolates. A cluster analysis of 178 scorable bands was used to identify 13 clusters, designated $\mathrm{A}$ to $\mathrm{M}$ (Fig. 6). Three RAPD clusters, D, G, and J, contained more than $88 \%$ (91) of the isolates. Cluster $\mathrm{G}$ with 58 isolates represented the most dominant and widely distributed genetic group in all the major Stylosanthesgrowing areas in Queensland (Table 1). Isolates in this cluster originated mainly from S. scabra plants. All 15 isolates in cluster D originated from $S$. scabra. In contrast, 14 of the 18 isolates in cluster $\mathrm{J}$ originated from host plants other than $S$. scabra. The remaining 12 isolates were contained in 10 other clusters, eight of which were represented by single isolates only (Fig. 6). Among these, five isolates, sr23, wrs8, wrs11, wrs35, and wrs52, were genetically distinct and originated from Stylosanthes spp. not grown widely in Australia. These isolates either belonged to race 1 or were weakly pathogenic. virulence groups and RAPD clusters among isolates studied in this work. Isolates of all three races came from more than one genetic background (Table 1). Seven different RAPD clusters were represented among isolates of each of races 1 and 3. Three RAPD clusters were represented among the smaller group of 13 race 4 isolates. However, a large number of isolates in specific RAPD cluster. For instance, 12 of 24 race 1 isolates were from RAPD cluster $\mathrm{J}$, and 32 of 47 race 3 isolates and 10 of 13 race 4 isolates were from RAPD cluster G.

Of the five most aggressive isolates, four, nq151, nq124, cs1443, and cs1571, were from RAPD clusters D and G, which contained other less aggressive isolates. Isolate nq244, on the other hand, is a new genotype with a distinct RAPD profile.

\section{DISCUSSION}

Highly aggressive isolates of C. gloeosporioides infecting the commercial cultivar Seca were detected from samples collected during recent years from a number
There was no clear association between each of the three races originated from a

of field sites in Queensland. One aggressive isolate, nq244, has a new genotype with a distinct RAPD profile, while the others have arisen from genetic groups that also contain other less aggressive isolates. This is a significant finding, given the high level of genetic uniformity within the biotype A pathogen population in Australia demonstrated in this and other studies $(1,20,21)$. Although a new race adapted to Seca was discovered within 6 years of its release (8), past surveys have shown that race 3 isolates cause only low to moderate damage to Seca (14). The 12 unclassified isolates did not represent a new virulence combination (race) but caused an increased amount of damage to Seca resulting from changes in their aggressiveness, as defined by Shaner et al. (25). When the search was narrowed from 103 to 19 isolates, the multivariate technique allowed the detection of the highly aggressive set of 12 isolates. Discovery of these isolates from different areas highlights a potential threat to the productivity and persistence of the most significant commercial Stylosanthes cultivar in Australia.

A significant relationship between severity on Seca and the year of collection of an isolate suggests an increase in aggressiveness toward Seca in the pathogen population. Because of the relatively small number of isolates examined, it is not possible to clearly establish whether $C$. gloeosporioides infecting Seca has gradually adapted to become more aggressive in the last two decades or whether highly aggressive isolates, already present in low numbers, have increased in frequency during the sampling period. There is evidence of adaptation for increased aggressiveness in Cochliobolus heterostrophus toward partially resistant corn (16) within three sexual generations of the pathogen. Similar evidence exists for other plant pathogens for which controlled crossing has shown that aggressiveness is heritable and may be polygenically controlled (2). Despite the existence of teleomorphic strains of $C$. gloeosporioides with low virulence on Stylosanthes spp. (18), there is no evidence
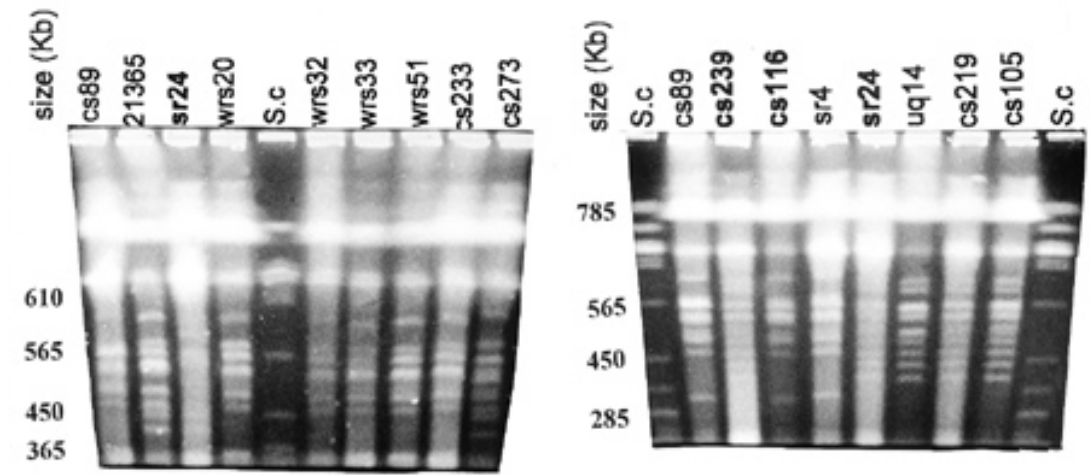

Fig. 5. Putative minichromosomes in isolates of Colletotrichum gloeosporioides determined with a contour-clamped homogeneous electric field dynamically regulated system used for electrophoretic karyotyping. Lanes marked "S.c" contain Saccharomyces cerevisiae chromosomes as size markers. of widespread genetic recombination between races and biotypes within Australia (20). However, heterokaryon formation through nitrate nonutilizing mutants in both biotypes and the introgression of a 2Mbp biotype A chromosome into biotype B isolates $(20,23)$ under laboratory conditions suggest the presence of parasexuality. Detailed genetic analysis of nq244 and other more aggressive isolates is needed to determine their origin.

In common with earlier work, we have observed variation in the number and size of DNA fragments, putatively referred to as minichromosomes (22). Masel et al. (24) classified isolates of C. gloeosporioides with fewer than six minichromosomes as Mtype 1 and isolates with six or more minichromosomes as Mtype 2. Six to 11 minichromosomes were resolved in the 21 isolates studied in this work. On the basis of earlier published work $(22,24)$ and the results presented in this study, we conclude that all Australian biotype A isolates belong to the Mtype 2 group.

Previous studies showed highly variable karyotype among isolates within biotype B $(22,24)$, despite the apparent monomorphy demonstrated by RFLP analysis $(1,20)$. In this work on biotype A, we recorded similar differences in EK within the apparently clonal groups identified by RAPD analysis. $\mathrm{He}$ et al. (11) showed that although the minichromosomes themselves have a very high degree of sequence homology, karyotype polymorphism arises from DNA addition, deletion, and rearrangement (20).

The majority of isolates obtained from hosts other than the two most dominant species in Australia, S. scabra and $S$. hamata, are either weakly pathogenic or pathogenic only on Fitzroy. This includes the five genetically distinct isolates from $S$. montevidensis, S. capitata, and S. guianensis. Although only a small number of isolates from $S$. hamata were used in this work, we showed previously that all races are prevalent in S. hamata pastures (12). This suggests that the more simple races of the Australian biotype A tend to infect a broader range of species, whereas races that infect a large number of differentials (complex races) are commonly isolated from S. scabra and S. hamata.

The overall weak association between virulence and genetic groupings in our study is consistent with findings from studies on $C$. gloeosporioides infecting $S$. guianensis in which virulence and isozyme (17) and RAPD markers were used (15). These results indicate that pathogenic races have arisen independently within each genetic group. Leung et al. (19) concluded that the association between molecular markers and virulence patterns in plant pathogens can be perfect, partial, or absent. Close association between virulence and selection-neutral molecular markers, such as RAPD, has been recorded in some pathogens (7). 


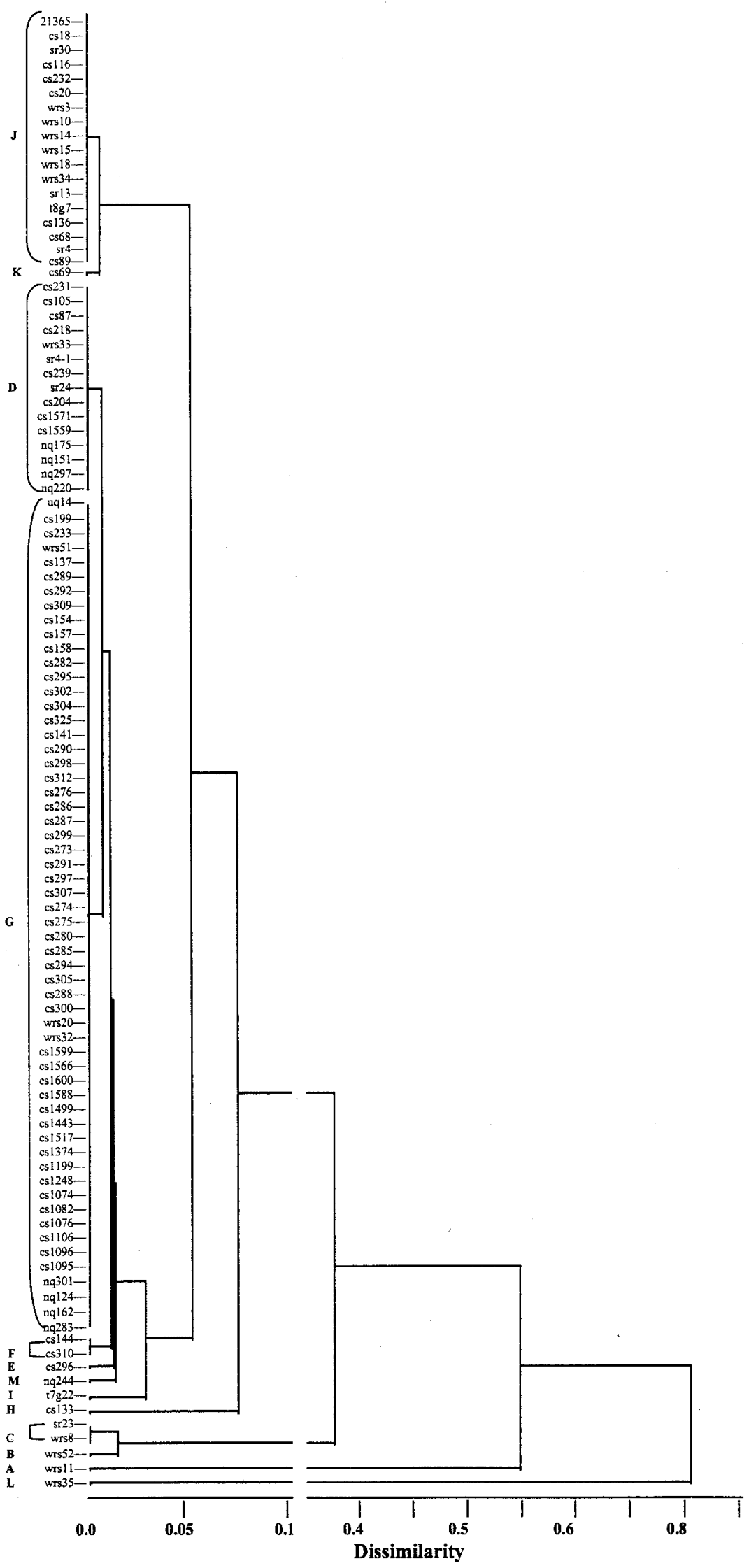

Fig. 6. Dendrogram of 103 single-spore isolates of Colletotrichum gloeosporioides infecting Stylosanthes spp. developed by random amplified polymorphic DNA analysis. Capital letter indicates the genetic group assigned to an isolate cluster.
The level of variation in the Australian population of $C$. gloeosporioides is limited compared with the extensive range of genetic and virulence diversity found at its center of origin in South America (3). The strict quarantine measures that exist today have helped to maintain this situation and must be continued for practical reasons. Given the potential for genetic recombination suggested by the EK analysis, any newly introduced overseas isolate may have the potential to recombine with welladapted Australian races to pose a serious threat to the industry.

Within Australia, isolates of C. gloeosporioides have become progressively more aggressive toward Seca. The five highly aggressive isolates originated from different genetic backgrounds. This fact and the existence of the same pathogenic races within different genetic backgrounds suggest that host-mediated selection is a major determinant of the pathogen population structure. There is a similar link between genetic groups and host of origin in biotype B isolates collected from $S$. guianensis in South America (15). Regular surveys must be taken to ascertain whether new races are arising as a result of deployment of new cultivars.

\section{ACKNOWLEDGMENTS}

We thank J. Irwin, R. Davis, and R. Trevorrow for providing some of the isolates used in this study. Financial assistance from the Australian Center for International Agricultural Research is gratefully acknowledged.

\section{LITERATURE CITED}

1. Braithwaite, K. S., Irwin, J. A. G., and Manners, J. M. 1990. Restriction fragment length polymorphisms in Colletotrichum gloeosporioides infecting Stylosanthes spp. in Australia. Mycol. Res. 94:1129-1137.

2. Caten, C. E., Person, C., Groth, J. V., and Dhali, S. J. 1984. The genetics of pathogenic aggressiveness in three dikaryons of Ustilago hordei. Can. J. Bot. 62:1209-1219.

3. Chakraborty, S., Charchar, M. J. d' A. Fernandes, C. D., and Kelemu, S. 1998. Genetic and pathogenic diversity in isolates of Colletotrichum gloeosporioides from eight species of Stylosanthes. Trop. Grassl. 31:393 401.

4. Chakraborty, S., and Jones, P. N. 1993. A rapid bioassay for the assessment of pathogenic variation in Colletotrichum gloeosporioides infecting Stylosanthes scabra. Plant Dis. 77:1016-1020.

5. Chakraborty, S., Thomas, M. R., and Ellis, N. 1996. A multivariate analysis of pathogenic variation in Colletotrichum gloeosporioides infecting the tropical pasture legume Stylosanthes scabra. Phytopathology 86:283-289.

6. Clements, R. J. 1996. Pastures for prosperity. 3. The future for new tropical pasture plants. Trop. Grassl. 30:31-46.

7. Crowhurst, R. N., Hawthorne, B. T., Rikkerink, E. H. A., and Templeton, M. D. 1991 Differentiation of Fusarium solani f. sp. cu curbitae races 1 and 2 by random amplification of polymorphic DNA. Curr. Genet. 20: 391-396.

8. Davis, R. D., Irwin, J. A. G., and Cameron, D. F. 1984. Variation in virulence and pathogenic specialisation of Colletotrichum gloeosporioides isolates from Stylosanthes cvs. Fitzroy 
and Seca. Aust. J. Agric. Res. 35:653-662.

9. Davis, R. D., Irwin, J. A. G., Shepherd, R. K., and Cameron, D. F. 1987. Yield losses caused by Colletotrichum gloeosporioides in three species of Stylosanthes. Aust. J. Exp. Agric. 27:67-72.

10. Edwards, K., Johnstone, C., and Thompson, C. 1991. A simple and rapid method for the preparation of plant genomic DNA for PCR analysis. Nucleic Acids Res. 19:1349.

11. He, C., Masel, A. M., Irwin, J. A. G., Kelemu, S., and Manners, J. M. 1995. Distribution and relationship of chromosome-specific dispensable DNA sequences in diverse isolates of Colletotrichum gloeosporioides. Mycol. Res. 99:1325-1333.

12. Iamsupasit, N., Cameron, D. F., Chakraborty, S., Gordon, G., Irwin, J. A. G., and Davis, R. D. 1991. Glasshouse and field evaluation of quantitative resistance to Colletotrichum gloeosporioides in Stylosanthes hamata tetraploids. Aust. J. Agric. Res. 42:429-439.

13. Irwin, J. A. G., and Cameron, D. F. 1978. Two diseases of Stylosanthes spp. caused by Colletotrichum gloeosporioides in Australia, and pathogenic specialisation within one of the causal organisms. Aust. J. Agric. Res. 29:305-317.

14. Irwin, J. A. G., Cameron, D. F., and Lenné, J.
M. 1986. Anthracnose problems with Stylosanthes. Pages 38-46 in: Proc. Aust. Conf. Trop. Pastures, 3rd. G. J. Murtagh and R. M. Jones, eds. Tropical Grasslands Society of Australia, Brisbane, Australia.

15. Kelemu, S., Badel, J. L., Moreno, C. X., Miles, J. W., Chakraborty, S., Fernandes, C. D., and Charchar, M. J. 1998. Genetic and pathogenic diversity in Colletotrichum gloeosporioides isolates from Stylosanthes guianensis. Trop. Grassl. 31:387-392.

16. Kolmer, J. A., and Leonard, K. J. 1986. Genetic selection and adaptation of Cochliobolus heterostrophus to corn hosts with partial resistance. Phytopathology 76:774-777.

17. Lenné, J. M., and Burdon, J. J. 1990. Preliminary study of virulence and isozymic variation in natural populations of Colletotrichum gloeosporioides from Stylosanthes guianensis. Phytopathology 80:728-731.

18. Lenné, J. M., and Parberry, D. G. 1976. Glomerella cingulata on Stylosanthes spp. in Northern Territories. Aust. Plant Pathol. Soc. Newsl. 5:24-25.

19. Leung, H., Nelson, R. J., and Leach, J. E. 1993. Population structure of plant pathogenic fungi and bacteria. Adv. Plant Pathol. 10:157-205.

20. Manners, J. M., and He, C. 1998. Molecular approaches to studies of Colletotrichum gloeo- sporioides causing anthracnose of Stylosanthes in Australia. Trop. Grassl. 31:435 444.

21. Manners, J. M., Masel, A. M., Braithwaite, K. S., and Irwin, J. A. G. 1992. Molecular analysis of Colletotrichum gloeosporioides pathogenic on the tropical pasture legume Stylosanthes. Pages 250-266 in: Colletotrichum: Biology, Pathology and Control. J. A. Bailey, and J. M. Jeger, eds. CAB International, Wallingford, UK.

22. Masel, A. M., Braithwaite, K. S., Irwin, J. A G., and Manners, J. M. 1990. Highly variable molecular karyotypes in the plant pathogen Colletotrichum gloeosporioides. Curr. Genet. 18:81-86

23. Masel, A. M., He, C., Poplawski, A. M. Irwin, J. A. G., and Manners, J. M. 1996. Molecular evidence for chromosome transfer between biotypes of Colletotrichum gloeosporioides. Mol. Plant-Microbe Interact. 9: 339-348.

24. Masel, A. M., Irwin, J. A. G., and Manners, J. M. 1993. Mini-chromosomes of Colleto trichum spp. infecting several host species in various countries. Mycol. Res. 97:852-856.

25. Shaner, G., Stromberg, E. L., Lacy, G. H., Barker, K. R., and Pirone, T. P. 1992. Nomenclature and concepts of pathogenicity and virulence. Annu. Rev. Phytopathol. 30:47-66. 